\title{
eCOti
DiAno
}

Revista Mídia e Cotidiano

Artigo Seção Temática

Volume 13, Número 3, dezembro de 2019

Submetido em: 27/09/2019

Aprovado em: 20/11/2019

\section{Contos à margem: letramentos de sobrevivência e midiativismo nas favelas do Rio de Janeiro}

\section{Tales on the margins: survival literacies and media activism in Rio de Janeiro's favelas}

\author{
Fernanda AMARAL ${ }^{1}$
}

\begin{abstract}
Resumo
A mídia mainstream no Brasil retrata as favelas de forma negativa, associando-as, desde o seu surgimento, com a pobreza, insalubridade e crime (VALLADARES, 2005; ZALUAR; ALVITO, 2006). Essa representação tendenciosa que colabora para a criminalização das favelas e sua gente não apenas traz prejuízos socioculturais, mas também influencia diretamente a legitimação da violência policial nesses locais. Este artigo discutirá a utilização das redes sociais e dos smartphones como ferramentas para desafiar a representação contemporânea das favelas na grande mídia como um lugar dominado pela violência - uma estrutura que foi disseminada em escala global e aceita como norma - e a luta dos moradores por voz, espaço e justiça nas favelas cariocas.
\end{abstract}

Palavras-chave: midiativismo; redes sociais; favelas; estigmatização.

\begin{abstract}
The mainstream media portray the favelas negatively in Brazil, associating them, since their emergence, with poverty, unhealthiness and crime (VALLADARES, 2005; ZALUAR; ALVITO, 2006). This biased representation that contributes to the criminalisation of the favelas and their people not only brings about socio-cultural damages but also directly influences the legitimation of police violence in these places. This article will discuss the use of social networks and smartphones as tools to challenge the contemporary representation of favelas in the mainstream media as a place dominated by violence - a structure that has been widespread on a global scale and accepted as the norm — and the struggles of residents for voice, space and justice in Rio's favelas.
\end{abstract}

Keywords: media actvism; social media; favelas; misrepresentation.

\footnotetext{
1 PhD in Media Discourse - Leicester Media School, Media Discourse Centre. E-mail: fmontamaral@gmail.com.
} 


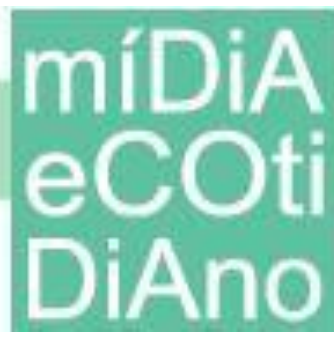

\section{Introdução}

O presente artigo tem como objetivo analisar a representação das favelas na grande mídia e seu impacto na legitimação da violência estrutural nesses locais, além de refletir sobre o papel das redes sociais como ferramenta na luta por voz e representatividade. A relação entre favelas, mídia e violência é tema complexo e diversos estudos se ocupam de sua reflexão. Esse artigo foca em um dos elementos dessa relação, o uso das redes sociais como instrumento de resistência à rotina de violência e abandono nas favelas.

Ao olhar para a favela a partir de questões acerca da representação na grande mídia e do midiativismo como ferramenta na produção de contranarrativas, esta pesquisa foi confrontada com o desafio de encontrar uma proposta metodológica que desse conta de uma análise de materiais variados e oferecesse profundidade de detalhes. Assim, empregou-se uma combinação de análise de conteúdo e etnografia virtual, de maneira que uma metodologia contrabalanceasse as fraquezas da outra, enriquecendo, assim, o resultado.

Considerando o caráter inquisitivo da pesquisa social que busca superar as barreiras da superficialidade e entender como as interações sociais desempenham seus papéis, uma abordagem virtual à etnografia crítica foi empregada na observação das interações dos moradores no ambiente online. Para esse estudo, foram observadas as interações ocorridas nas páginas do Facebook dos grupos Voz das Comunidades, Maré Vive e Coletivo Papo Reto. O trabalho etnográfico virtual se estendeu de 2014 a 2018 e teve como base teórica a abordagem de Hine (2000), permitindo situar o discurso dos moradores em seu contexto social, para que se pudesse observar como o conhecimento é moldado de acordo com as relações diárias e práticas culturais.

Complementar à etnografia virtual, foi feito levantamento, seguindo os conceitos da análise de conteúdo combinada sugerida por Macnamara (2005), dos jornais O Globo e Extra no ano de 2015, com o objetivo de verificar se a narrativa da favela como local de crime e violência verificado por Vaz e Baiense (2011) permanecia hegemônica.

A grande mídia do Brasil retrata as favelas de forma predominantemente negativa (AMARAL, 2019a). É notável que desde o surgimento dos primeiros conglomerados, esses espaços têm sido associados à pobreza, à insalubridade e ao crime 


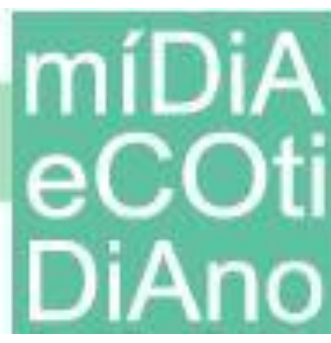

(ZALUAR; ALVITO, 2006; VALLADARES, 2005), "o lugar por excelência da desordem" (ZALUAR; ALVITO, 2006, p. 14). As narrativas atreladas a esses locais sempre foram as de que eram uma mancha na paisagem, uma patologia social e um problema de saúde pública e, a partir dos anos noventa, esse discurso se estendeu para apontar a favela como o "epicentro da violência urbana" (BARONI; AGUIAR; RODRIGUES, 2011, p. 313). Os contornos de uma cidade partida (VENTURA, 1994), em que parte da população está compulsoriamente desprovida de voz e representação, foram contestados a partir da popularização dos smartphones nas favelas, que contribuiu para o fortalecimento das lutas por espaço, voz e justiça.

Abordar temas como representação e identidade nas favelas nos conduz, acima de tudo, a reflexões sobre racismo e segregação social, uma vez que as raízes das favelas estão diretamente ligadas à história dos povos escravizados no Brasil (AMARAL, 2019a), e atualmente 67\% dos residentes das favelas são negros (MEIRELLES; ATHAYDE, 2014). Os regimes racializados de representação (HALL, 1997) que já se cristalizaram como a forma padrão de se representar esses espaços no Brasil (AMARAL, 2019a) trazem significantes impactos nas relações entre tais comunidades, o Estado e a sociedade, especialmente no que diz respeito à atuação da Polícia nesses territórios e às reações do Estado e da população aos homicídios em seus becos e vielas.

Embora não se possa responsabilizar unicamente a grande mídia pela criação dessa representação, fruto de um complexo emaranhado que envolve, entre outras coisas, as raízes escravistas e racistas das elites brasileiras e o surgimento e fortalecimento do crime organizado que assola vastas regiões do país, deve-se reconhecer seu papel na difusão e cristalização dessa representação no imaginário coletivo, construindo, assim, um "universo cognitivo específico a partir do qual passamos a interpretar os eventos ligados a ela (a favela)" (VAZ; BAIENSE, 2011, p. 2).

Com o objetivo de avaliar o panorama da cobertura das favelas pela mídia mainstream no Rio de Janeiro e verificar se o quadro encontrado por Vaz e Baiense em 2011 permanecia o mesmo, foi realizado um levantamento estatístico dos jornais O Globo e EXTRA, categorizando cada uma das reportagens sobre favelas no período estudado. $\mathrm{O}$ percentual de reportagens com foco em questões de crime e violência correspondeu a 67\% (AMARAL, 2019a, p. 183) e 79\% (Ibid., p. 130) das notícias tinham um 


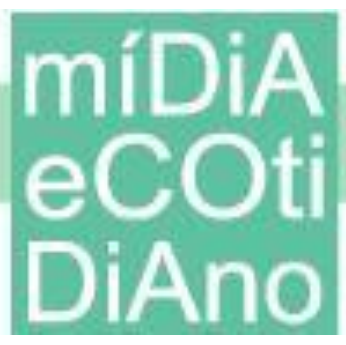

enquadramento negativo, demonstrando que esse tipo de estrutura, que reporta a favela como um local de violência e criminalidade apenas, e que se consolidou a partir de 2010 (VAZ; BAIENSE, 2011), é ainda hegemônico (AMARAL, 2019a).

Embora importante na compreensão do problema da representação das favelas, o enquadramento da violência não é o maior dilema na cobertura jornalística das favelas no Rio de Janeiro. O fato de haver violência nas favelas e essa violência ser reportada não constituiria ponto relevante à discussão, uma vez que, embora possa argumentar-se a favor de haver mais espaço para pautas positivas, o mero ato de reportar fatos, sejam eles negativos ou não, não deve, isoladamente, ser apontado como ponto a se contestar. $\mathrm{O}$ problema mais grave na atual forma de se cobrir as favelas, então, encontra-se na “dependência em alto grau” (RAMOS; PAIVA, 2007, p. 37) da versão oficial (a da polícia), sem que haja minucioso trabalho de apuração, ouvindo, por exemplo, testemunhas. A imprensa tende a explorar tópicos relacionados aos diversos tipos de violência que assolam as favelas e periferias, como o tráfico de drogas, a truculência policial e as milícias, mas "as vozes e perspectivas dos moradores das favelas raramente são representadas" (BARONI; AGUIAR; RODRIGUES, 2011, p. 310). Uma pesquisa realizada pelo CeSEC, mostrou que a Polícia foi a principal fonte ouvida em 43,2\% das reportagens que abordavam violência e criminalidade no país; especificamente no Rio de Janeiro 26,9\% dos casos relatados em oito jornais foram baseados exclusivamente em informações obtidas através dos policiais (RAMOS; PAIVA, 2007, p. 37).

Essa prática de colocar a Polícia e os órgãos de segurança pública como as únicas fontes na cobertura de eventos relacionados à favela corrobora a crença já estabelecida de que esses locais são o epicentro do crime e do caos urbano (TERRA; CARVALHO, 2015), através da manipulação da narrativa jornalística, que retrata o morador da favela como criminoso ou suspeito e apresenta, por exemplo, o assassinato de jovens trabalhadores pela polícia como resultado de uma troca de tiros (CAPRIGLIONE, 2015, p. 58).

Essa representação apresenta-se como principal fator na legitimação da violência policial (AMARAL, 2019a), uma vez que a mídia é a principal responsável pela mobilização da opinião pública e vem consolidando sistematicamente essa visão estigmatizada que divide a cidade e torna o morador da favela "o outro", desligando-o da 


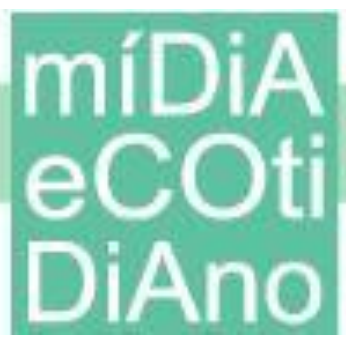

cidade formal e vinculando-o à "marca do perigo", a uma "condição desviante" (RINALDI, 2006, p. 307), que, precisa, portanto, ser combatida com robustez pelas forças de segurança pública. Contribui, assim, para a aceitação e até a demanda por mais polícia e também por uma polícia cada vez mais brutal, tolerando, banalizando e até incentivando essa brutalidade, "representada por tortura em delegacias e prisões, execuções extrajudiciais à luz do dia, prisões arbitrárias e, finalmente, indiferença a qualquer garantia constitucional e respeito a direitos humanos" (WYLLYS, 2015, p. 53):

A opinião pública e a mídia, então, clamam por mais repressão, mesmo que à margem do Estado de Direito. Zaffaroni (2011) fala que as mortes por execuções sem processo são naturalizadas na mídia e na opinião pública uma vez que atingem sempre eles, os outros, os inimigos, os criminalizados, o jovem negro da favela - que se pressupõe criminoso (VALENTE, 2012, p. 211).

Esse processo envolve ainda a produção do medo social como impulsionador do aumento do preconceito e estigmatização contra as favelas, resultando em evasão social e indiferença em relação à criminalização dos pobres. Os meios de comunicação de massa desempenham um papel central nesse processo, na medida em que produzem, moldam e reforçam a opinião pública, espalhando medo e reproduzindo narrativas e imagens estereotipadas sobre os moradores das favelas (RAMOS; PAIVA, 2007).

A produção do medo social através da perspectiva do outro e da narrativa da favela como "lugar de grande perigo" e um "meio marginal" capaz de "produzir bandidos" (RINALDI, 2006, p. 308) e trazer o caos à cidade formal, também descrito por Chalhoub (1988) como "medo branco de almas negras", resulta, então, em indiferença à criminalização e genocídio nas favelas. Nesse cenário, a grande mídia não apenas estimula reproduzindo ideias estereotipadas sobre a favela e seus moradores, mas também contribui para a prática de violência policial nesses locais, através de uma colaboração tácita em que publiciza a versão da Polícia e ignora as vozes locais. O coronel da Polícia Militar Augusto Severo resumiu a relação da corporação com a mídia e o papel dela na legitimação do modo operacional da PM através da formação da opinião pública:

Nós nos acostumamos a gerenciar a imprensa de três maneiras. Primeiro, obstruindo a ação do jornalista, tentando impedi-lo de ver e 
relatar o que fazíamos. Segundo, permitindo a atuação da imprensa, mas apresentando uma realidade maquiada: inventávamos as famosas histórias de cobertura e mostrávamos uma realidade que não existia. Por último, ignorávamos a imprensa e evitávamos o diálogo. [...] Legitimidade é dada pela opinião pública, e quem nos ajuda a formar a opinião pública é a imprensa (RAMOS; PAIVA, 2007, p. 47).

Rinaldi (2006), acrescenta ainda à discussão sobre a criminalização das favelas que o próprio sistema judiciário é carregado de estigma contra o morador desses locais, o que afeta diretamente o resultado de julgamentos que venham a envolvê-los, seja como réus ou vítimas. Segundo a autora, mesmo quando os profissionais do Direito "procuram renegociar a identidade do favelado, o ponto de partida é o estigma, o lugar da 'anormalidade', da anomia, da carência" (Ibid., p. 318). Todo esse contexto deixa claro para o policial que comete violência nesses locais que mesmo que as vozes das vítimas sejam ouvidas, as chances de um processo são mínimas - apenas cerca de 3\% dos autos de resistência se tornam processos no Rio de Janeiro (AMARAL, 2019b, p. 168) - e ainda que haja um processo, o morador das favelas é visto de maneira estigmatizada também pelo sistema judiciário - tudo isso com a colaboração da imprensa, que, na maioria das vezes, ignora outras versões que não a da Polícia.

Esse cenário aponta para a conclusão de que essa imagem tendenciosa da favela difundida pela mídia e reforçada pela ausência de representatividade real tem contribuído para a perpetuação e fortalecimento das desigualdades sociais, exclusão, racismo e outros abusos (AMARAL, 2019a), tornando-se uma forma de violência simbólica (BOURDIEU, 1990), que criminaliza uma população já marginalizada e legitima a violência estrutural contra ela, contribuindo para o já significativo processo de segregação social. Um contraponto a esse delicado sistema de exclusão, que envolve deturpação e sub-representação, é a recente popularização das novas tecnologias de comunicação nessas comunidades e a mobilização de seus residentes através delas.

\section{Letramentos de sobrevivência: novas tecnologias como aliadas na luta por voz}

O acesso ao consumo, resultado de políticas públicas que possibilitaram alguma mobilidade social e ascensão financeira das camadas pobres, resultou na popularização dos smartphones nas favelas na última década (MEIRELLES; ATHAYDE, 
2014), levando a internet - e as redes sociais - para o bolso dos moradores. Essa mudança pode ser apontada como o ponto de partida para uma nova forma de lutar por uma vida melhor: conectados através de seus smartphones, os moradores passaram a usar as redes sociais para discutir a favela, reclamar direitos e cobrar melhorias ao poder público.

Antes de discutir a utilização das redes sociais para fins de ativismo, é preciso, porém, considerar brevemente o papel das redes sociais na construção e reafirmação da identidade da favela. Embora a definição mais ampla de identidade aponte para um conjunto de características relacionadas a um indivíduo que permita que essa pessoa seja identificada como sujeito e que a diferencie das outras, Liliana Giorgis (1993, p. 5) argumenta que "uma identidade autorreferencial construída sobre os princípios da lógica abstrata, não pode explicar as transformações e diferenças socioculturais", levando à conclusão de que o conceito de identidade vai além da definição ampla de um conjunto de características e inclui fatores muito mais complexos, como a personalidade individual, escolhas e oportunidades pessoais, além da conjuntura cultural em que o indivíduo está inserido.

Zhao, Grasmuck e Martin (2008), defendem que redes sociais são capazes de permitir que minorias estigmatizadas deixem de se identificar apenas com as características a elas atribuídas (no caso das favelas predominam a pobreza e a criminalidade), e construam uma imagem mais positiva de si mesmos. Isso acontece porque nas redes sociais o usuário é o dono da sua própria narrativa, e o fato de estar online ajuda a remover barreiras estigmatizantes que posariam como obstáculos no mundo real. Isso implica dizer que enquanto no mundo real um jovem da favela pode ser pré-julgado pela cor da sua pele e vestimentas ou mesmo pelos trejeitos e já iniciar um diálogo em posição de desvantagem devido aos estigmas atrelados à sua identidade, no mundo virtual esse mesmo jovem tem a oportunidade de ultrapassar essas barreiras, deixando de lado as características a ele atribuídas e destacando as que o próprio considera mais importantes sobre si mesmo, e de trazer outra perspectiva (uma positiva, de valorização) às idiossincrasias tão estigmatizadas da cultura favelada.

Assim, a internet se estabelece como uma ferramenta que possibilita que as minorias estigmatizadas ganhem voz para conduzir suas próprias narrativas e produzir conteúdo (AMARAL, 2019a; TACCHI, 2009), desconectada da dinâmica da mídia 


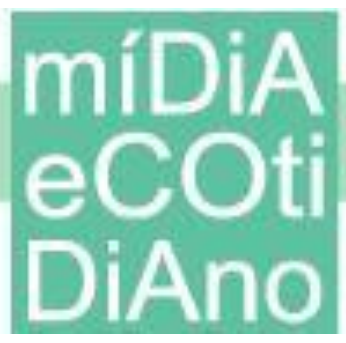

tradicional que representa a favela sem dar-lhe voz, uma vez que se apresentam como “espaços de autonomia, muito além do controle dos governos e empresas - que, ao longo da história haviam monopolizado os canais de comunicação como alicerces de seu poder" (CASTELLS, 2015, p. 2).

Com isso em mente, parte-se para a discussão da busca por voz e espaço no campo democrático por meio do midiativismo. Embora amplo, o conceito de voz é delineado pela ideia de que voz é um instrumento de inclusão através da sua capacidade de expressão e criação de significado e de participação em processos econômicos e sociais (AMARAL, 2019a; TACCHI, 2009). Torna-se, portanto, fundamental à democracia, que necessita de uma pluralidade de vozes para existir (LAWY, 2017), e primordial na luta por igualdade, reconhecimento político e garantia dos direitos fundamentais, uma vez que só exige direitos aquele que figura no campo do debate democrático (CAPRIGLIONE, 2015).

Lawy (2017) defende ainda que através da voz é possível ultrapassar as barreiras das experiências pessoais e conectar minorias por meio de experiências compartilhadas e, finalmente, define voz como "uma maneira de um ator social decretar ou realizar sua identidade e usar sua própria agência" (2017, p. 197) e que está relacionada ao poder e à autoridade de ter voz e de reivindicar voz (Ibid., p. 195). Voz, portanto, apresenta-se como um instrumento de poder no debate democrático onde aqueles que possuem a "autoridade de ter voz" (Ibid.) encontram-se em situação de privilégio em relação àqueles que não têm.

As relações de voz e poder levam à reflexão da conexão entre (ausência de) voz e pobreza. Há uma tendência, quase padronizante, de populações que vivem na pobreza e exclusão também enfrentarem o fenômeno descrito por Tacchi (2009) como "pobreza de voz": "a incapacidade das pessoas de influenciar as decisões que afetam suas vidas e o direito de participar dessas tomadas de decisão" (TACCHI, 2009, p. 169). Essa pobreza de voz fica evidente quando nos debruçamos sobre as narrativas a respeito da favela: não há espaço para as vozes faveladas na mídia que, majoritariamente, só ouve a versão do Estado dos eventos; não há espaço para vozes faveladas no sistema judiciário, que durante os inquéritos não os ouve e já nos tribunais os enxerga sob uma perspectiva estigmatizada; não há espaço para as vozes faveladas na cidade, que enxerga a favela como uma "anomalia" e ignora sua criminalização. Nesse cenário, faz-se importante, então, considerar como as 


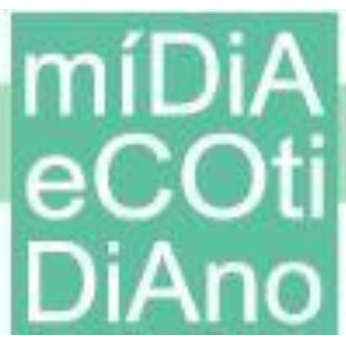

redes sociais estão alterando dinâmicas sociais já cristalizadas e permitindo que os moradores das favelas conquistem espaço para contar suas próprias narrativas.

A emergência das mídias sociais alterara de diversas formas a maneira de se fazer jornalismo e produzir conteúdo, provocando mudanças especialmente nas relações de interlocução. Hoje observa-se um modelo mais horizontal, que engloba mais pessoas como produtores de conteúdo (papel antes centralizado na figura do jornalista) e possibilita que a agenda da mídia não seja inteiramente controlada pelos grandes conglomerados (LOPES; ALVES, 2011). Nesse modelo, considerando a relevância das redes sociais e do vídeo amador, os papéis de produtor e consumidor de notícias se sobrepõem, sendo potencialmente possível a qualquer cidadão produzir e compartilhar informações (JENKINS, 2008; LÉVY, 1999) - uma pessoa que testemunha um crime e filma usando seu celular pode se tornar a principal fonte de informações sobre tal evento, seja compartilhando esse conteúdo online, seja enviando esse conteúdo bruto para veículos de comunicação:

Graças ao crescimento das mídias sociais, as notícias não são mais reunidas exclusivamente por repórteres e transformadas em uma história, mas surgem em um ecossistema no qual jornalistas, fontes, leitores e espectadores trocam informações (LOPES; ALVES, 2011, p. 112).

Em 2010, um caso envolvendo a megaoperação de invasão do Complexo do Alemão para a instalação da UPP (Unidade de Polícia Pacificadora) e a utilização das redes sociais por moradores de favelas ganhou repercussão internacional. Os moradores em questão eram os jovens responsáveis pelo jornal comunitário A voz da Comunidade, criado por Rene Silva, que usavam o Twitter para narrar em tempo real a situação dentro do complexo de favelas.

Além da informar sobre aquilo que viam de suas próprias janelas - os jornalistas estavam todos aglomerados nas entradas das favelas e só tinham acesso às informações da Polícia e do helicóptero - os jovens recebiam relatos de outros moradores de diversas localidades dentro do Alemão através do celular e das redes sociais. Chegaram, inclusive, a corrigir informações imprecisas veiculadas pela imprensa (ABREU, 2013). O perfil do jornal (@avozdacomunidade) no Twitter passou de apenas 


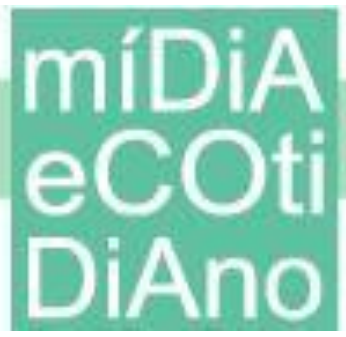

180 seguidores antes da ocupação para mais de 30.000 em apenas três dias e, através das narrativas de dentro para fora da favela, foi capaz de impactar inclusive a cobertura da mídia mainstream (LOPES; ALVES, 2011).

De 2010 em diante esse movimento de tomada das redes sociais como ferramenta de emancipação nas favelas se intensificou (AMARAL, 2019a) e um dos resultados foi o surgimento dos "coletivos" de notícias - grupos de moradores que se organizam para reportar e discutir o que acontece nas favelas. Esses moradores estão desenvolvendo conhecimento de como empregar o potencial das redes sociais em diversas frentes na luta por dignidade e justiça. O Coletivo Papo Reto, por exemplo, tem uma atuação bastante crítica à Polícia e ao Estado (AMARAL, 2019a) e tem exercido um papel essencial dentro da rotina de violência que vitimiza os moradores das favelas: o de funcionar como garantia de que a atuação da polícia não será mascarada através da alteração da cena do crime, que simula "mortes em enfrentamento" (ZAFFARONI, 2011, p. 375) para encobrir execuções, ao rapidamente se deslocarem às cenas de crime com câmeras e celulares.

Já o 'Voz da Comunidade' utiliza uma combinação de redes sociais e jornal impresso na sua cobertura jornalística da favela, destacando eventos culturais e notícias positivas (AMARAL, 2019a). A esse conjunto de ações utilizando mídias tradicionais (como o jornal impresso ou rádio) e as novas mídias (como as redes sociais e blogs) contestando a política vigente, Custódio (2016) chamou de "midiativismo de favela":

Ações individuais e coletivas de moradores de favelas na, através da, e sobre a mídia. [...] Ao se envolver em midiativismo dentro, fora e entre favelas, moradores geram conhecimento crítico entre moradores, geram debates públicos, formam novos públicos e mobilizam ações contra ou em reação às consequências materiais e simbólicas da desigualdade social no cotidiano (CUSTÓDIO, 2016, p. 22).

A necessidade de registrar a atuação da polícia nas favelas não é algo novo para seus residentes e ativistas. Mais do que gerar provas da conduta violenta da Polícia, esses moradores vêm buscando maneiras de proteger a memória daqueles que são assassinados pois, uma vez que testemunhas raramente são ouvidas nas investigações como discutido acima, essas mortes são registradas como legítima defesa e, portanto, as 
vítimas figuram como criminosos. A atuação dos ativistas nas favelas em um movimento de educar os moradores a filmar casos de violência policial e a conduta de preservação da cena do crime vem surtindo efeitos e cada vez mais vídeos emergem para contestar a versão oficial (a da polícia). Nos momentos imediatamente após o assassinato do menino Eduardo de Jesus, no Complexo do Alemão, em 2015, os moradores pediam por alguém que pudesse filmar a cena do crime ${ }^{2}$, evidenciando que a importância do vídeo como ferramenta de denúncia e de defesa já permeia o saber popular nesses locais. Carlos Coutinho, do Coletivo Papo Reto, também defende que a postura da Polícia muda quando há câmeras, sendo até mesmo capaz de coibir abusos. A presença do grupo na cena do crime após a morte de Eduardo garantiu a integridade dela, evitando, inclusive, que uma arma fosse plantada pelos próprios policiais no local ${ }^{3}$, como aconteceu nos casos de Alan e Chauan na Palmeirinha ${ }^{4}$ e de Eduardo Felipe Victor dos Santos ${ }^{5}$, na Providência, ambos também em 2015.

Nesse sentido, a organização WITNESS ${ }^{6}$, que se dedica a difundir o uso do vídeo como ferramenta de defesa dos direitos humanos, em parceria com o Coletivo Papo Reto, divulga nas redes sociais um guia preparado para orientar cidadãos comuns a utilizarem seus celulares para filmar a ação da polícia:

\footnotetext{
${ }^{2}$ Disponível em: <https://bit.ly/2L59fNO>. Acessado em: 26 set. 2019.

${ }^{3}$ Fonte: Anistia internacional, "Você matou meu filho", p. 20, 2015. Disponível em: <https://bit.ly/2OA6Ywp>. Acessado em: 26 set. 2019.

${ }^{4}$ Reportagem sobre o caso da Palmeirinha. Disponível em: 〈https://bit.ly/2R9oSr8>. Acessado em: 23 set. 2019.

${ }^{5}$ Reportagem sobre o caso do Morro da Providência. Disponível em: 〈https://glo.bo/37PaNVR>. Acessado em: 23 set. 2019.

${ }^{6}$ WITNESS: Disponível em: <https://bit.ly/34zi9uu>. Acessado em: 26 set. 2019.
} 
Figura 1 - Como filmar violência policial na favela com celular

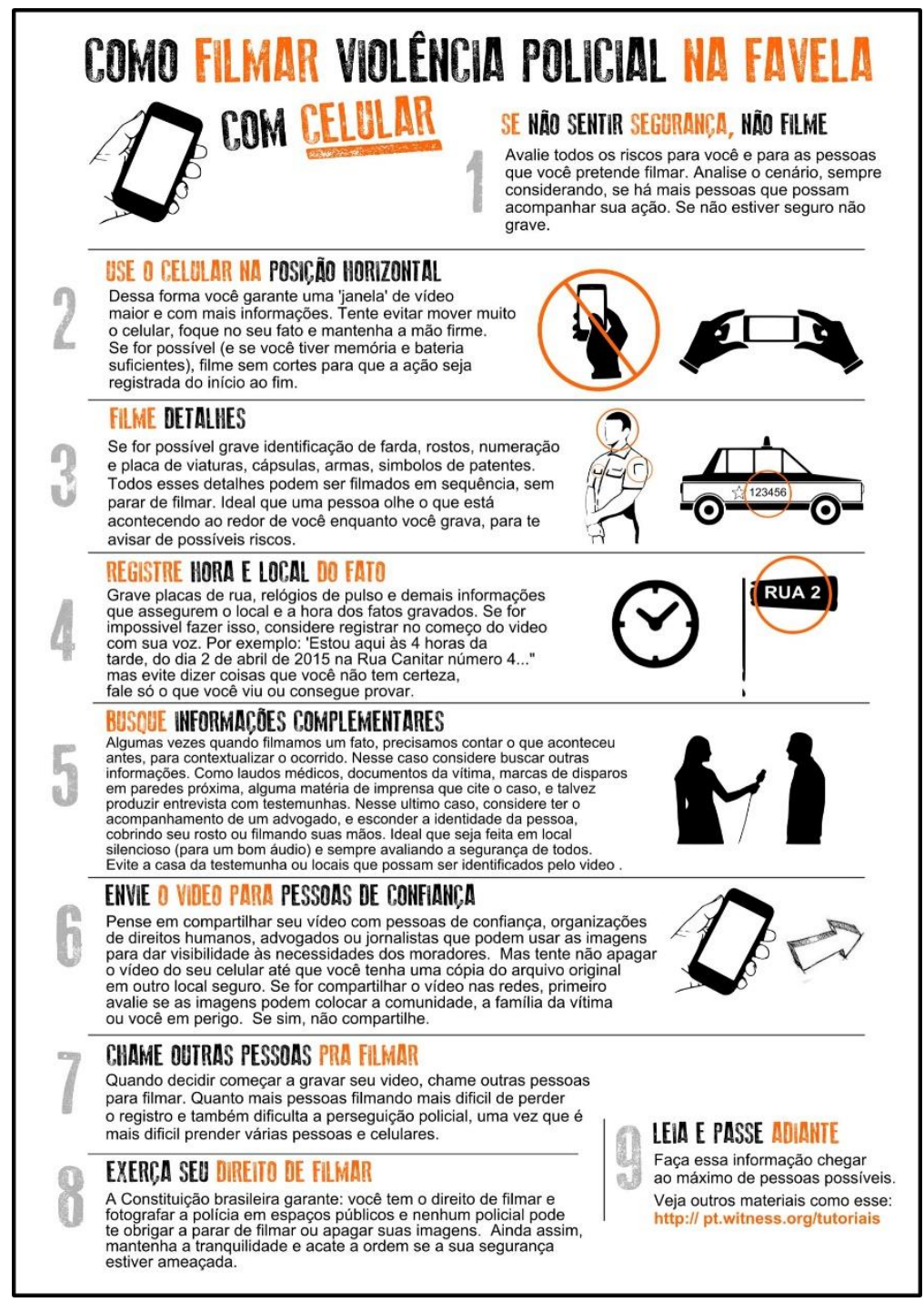

Fonte: WITNESS.

Esse esforço em favor de tornar o vídeo e o uso sistemático das redes sociais parte do repertório de resistência (DELLA PORTA; DIANI, 2006; MCCURDY; FEIGENBAUM; FRENZEL, 2016) nas favelas e empoderar esse grupo estigmatizado e sem voz na mídia mainstream (AMARAL, 2019a) é significativo especialmente se considerarmos que a audiência online já ultrapassa a mídia impressa no mundo e no Brasil já são equivalentes (LOPES; ALVES, 2011, p. 117). Nos últimos anos esse processo de letramento vem transformando residentes em midiativistas que hoje "dominam cada vez mais os canais e plataformas de comunicação para fazer ouvir suas vozes e demandas" (CUSTÓDIO, 2014a, p. 3), assumindo um papel ativo no processo de produção de 


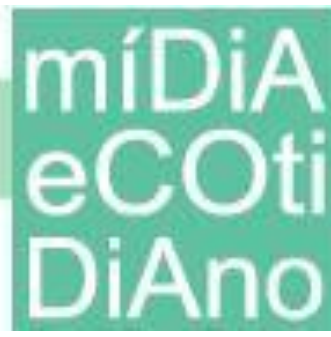

notícias da favela (seja produzindo o conteúdo final, seja informando os coletivos dos eventos ocorridos ou ainda compartilhando).

A atuação dos moradores online também encontra exemplos de caráter preventivo. Durante um estudo minucioso das atividades do grupo Maré Vive (AMARAL, 2019a), um canal colaborativo de mídia comunitária na Maré, descobriu-se que além da atuação crítico-reflexiva dos integrantes do grupo ao discutir as condições de vida no local, especialmente relacionadas à atuação da Polícia, o perfil também exerce o importante papel de informar os moradores sobre operações policiais, tiroteios e outras situações de risco (Ibid.).

Embora outros midiativistas também adotem esse tipo de abordagem, o Maré Vive tem uma atuação de destaque nesse sentido pois não apenas recebe informações dos moradores sobre conflitos, mas também os encoraja ativamente a compartilhar a situação em tempo real do local onde vivem, com posts quase diários perguntando sobre a situação na favela. Os responsáveis pelo grupo, que atuam de forma anônima, se apoiam nessa colaboração dos moradores para cobrir a extensa área da Maré e em 2015 o número de posts no Facebook com o intuito unicamente de avisar aos demais moradores sobre as condições de risco no local chegou a 18\% do total (AMARAL, 2019a).

Figura 2 - Post da página Maré Vive, em fevereiro de 2017

Bom dia! Como estamos hoje? Algumas pessoas estão perguntando se
haverá aula hoje nas escolas.. vamos nos comunicar.
103 Comment
$\square$ Like

Fonte: Reprodução da página Maré Vive no Facebook.

Castells (2015) defende que os movimentos sociais nascem das condições insustentáveis de vida para determinado grupo e são as alavancas da mudança social, "induzidos por uma profunda desconfiança nas instituições políticas que administram a sociedade" (CASTELLS, 2015, p. 246), levando as pessoas a tomarem a ação para si, uma vez que acreditam que as autoridades não resolverão o problema. Em um país em 


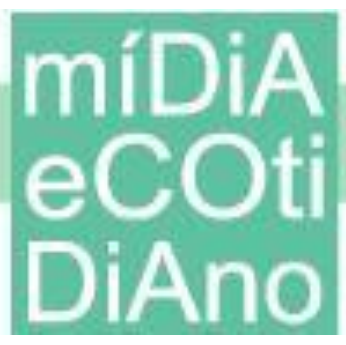

que $70 \%$ da população não confiam na Polícia, $63 \%$ estão insatisfeitos com a sua atuação e um terço da população vive com medo da violência policial (MENA, 2015, p. 21), não surpreende que as populações que vivem às margens da cidade busquem maneiras de se protegerem da própria polícia. Nas favelas, menos de $4 \%$ das pessoas acreditam que as melhorias que conquistam em suas vidas são fruto das políticas públicas (MEIRELLES; ATHAYDE, 2014, p. 30), outra face da descrença nas instituições políticas. Essa conjuntura de indignação e descrença encontrou na emergência das redes sociais a oportunidade para o fortalecimento dos movimentos sociais dentro das favelas.

Movimentos sociais são "práticas de indivíduos desafiando o status quo para provocar mudanças sociais, políticas ou econômicas" (HARLOW; GUO, 2014, p. 465). Toch (1965, p. 5, apud OPP 2009, p. 35) os define como "esforços de um grande número de pessoas para resolver coletivamente um problema que eles sentem que têm em comum", assim como Jenkins e Form (2005, apud OPP 2009, p. 35), que também destacam o caráter organizacional em prol de um bem coletivo, defendendo que os movimentos sociais são "esforços organizados para promover mudanças sociais".

Zald, McCarthy e Gamson (2017) destacam ainda o caráter voluntário desses movimentos, nos quais as pessoas que compartilham de uma identidade coletiva (Maiba, 2005), se unem em apoio mútuo a fim "de mudar indivíduos ou instituições e estruturas sociais" (ZALD; ASH, 1966, apud OPP 2009, p. 35). São ainda "emocionalmente motivados" (CASTELLS, 2015), pois devido ao seu caráter arriscado, uma vez que desafiam a ordem social e a classe detentora de poder, necessitam de forte motivação, geralmente desencadeada por um evento significativo que faz com que o grupo oprimido vença a barreira do medo e ponha-se em ação contra o opressor.

Em conclusão, os principais critérios (coletivo de indivíduos, objetivos compartilhados orientados para a mudança, atividade, continuidade) usados para definir movimentos sociais por teóricos (DELLA PORTA; DIANI, 2006; MAIBA, 2005; TARROW, 1998; TILLY, 1978; ZALD; MCCARTHY; GAMSON, 2017) podem ser observados no midiativismo de favela, colocando esse fenômeno sob a égide da teoria dos movimentos sociais.

Historicamente, a mídia mainstream retrata os ativistas, de favela ou não, de uma perspectiva tendenciosa, que demoniza aqueles que protestam e desvaloriza suas 


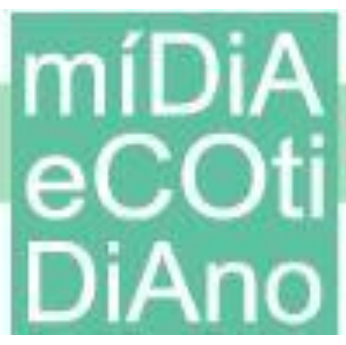

causas, conhecida como paradigma de protesto (MCLEOD; HERTOG, 1999). Tal prática, que se utiliza de mecanismos de marginalização dos ativistas, é rotineira (MCLEOD; HERTOG, 1999) e está inserida no contexto mais amplo de enquadramento (GOFFMAN, 1974). Com o surgimento das redes sociais, as ferramentas online assumiram um papel de mediadoras entre os eventos e ativistas e as demais pessoas (MACLEOD, 2016), outrora exercido apenas pela grande mídia, atuando como uma forma de mídia alternativa na busca de uma representação mais fidedigna e menos negativa, além de "galvanizar e organizar a atividade" (MACLEOD, 2016, p. 91).

Nas favelas, as redes sociais se tornaram uma ferramenta capaz de unificar vozes dissonantes em torno de um objetivo comum (AMARAL, 2019), através de esforços comunitários apoiados na noção de identidade coletiva, definida como "a conexão cognitiva, moral e emocional de um indivíduo com uma comunidade mais ampla” (POLETTA; JASPER, 2001, p. 285). No caso das favelas, está ligada ao território ocupado (a favela) e aos traços socioculturais de sua gente (AMARAL, 2019a). Assim, moradores de diversas favelas se unem - no mundo real ou virtual - ora ao esforço de um grupo ora ao esforço de outro, uma vez que ainda que em favelas diferentes a causa que os une permanece a mesma: as condições de vida, os abusos, a violência, o abandono; as dores da comunidade que por falta de voz acabam se tornando "invisíveis aos olhos da sociedade fora da favela" (CUSTÓDIO, 2014b, p. 150).

McCurdy, Feigenbaum e Frenzel (2016) observaram que campos de protesto, como aqueles montados pelo movimento "Occupy" ou mesmo as escolas brasileiras ocupadas por estudantes, "formam espaços nos quais uma variedade de repertórios de contendas são desenvolvidos, experimentados e testados, difundidos ou, às vezes, descartados". (Ibid., p. 98) Nesses espaços, surgem práticas que se consolidam e se espalham ao redor do mundo, como o microfone humano, por exemplo, em que para driblar a proibição de amplificadores, as pessoas ao redor repetem um uníssono o discurso sendo proferido, possibilitando, assim, que todos ouçam. Nas favelas ocorre um fenômeno muito semelhante ao observado por McCurdy, Feigenbaum e Frenzel (2016) nos campos de protesto: o desenvolvimento de táticas online (grupos nas redes sociais, blogs, etc.) e sua integração com as ruas da favela real e com táticas off-line que tomam a cidade ocupando seu território em atos de dissidência. Transformam, assim, as duas, 


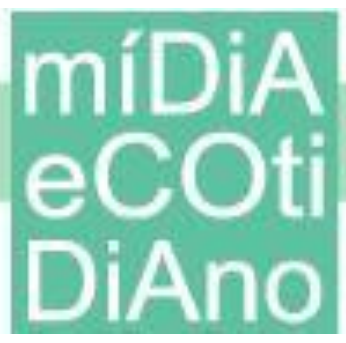

favela e cidade, em locais de protesto e desafiam as concepções dominantes sobre a primeira na grande mídia e na sociedade, criando, adaptando e consolidando repertórios de resistência (DELLA PORTA; DIANI, 2006; MCCURDY; FEIGENBAUM; FRENZEL, 2016) nas favelas.

Esses repertórios de resistência então se consolidam e se tornam parte da rotina. O sistema de avisos do Maré Vive no Facebook, por exemplo, passa a integrar a chegada do morador às favelas, com o hábito de checar na página do grupo se há conflitos naquele momento antes de entrar no local (AMARAL, 2019a). O ato de filmar violência policial também passa a integrar o repertório de resistência das favelas, sendo repetido vez após vez e passando a ser um ato quase automático; assim como o uso em si das redes sociais, especialmente Facebook, Twitter e WhatsApp, para divulgar informações sobre eventos ocorridos nesses territórios.

A utilização dessas tecnologias, embora só recentemente tenha se popularizado nas favelas, cresce de maneira acelerada (MEIRELLES; ATHAYDE, 2014) e os residentes desses locais vêm aprendendo rapidamente não apenas o manuseio, mas a importância delas na resistência favelada. O caso de Eduardo Felipe dos Santos Victor, no Morro da Providência, ilustra bem a consolidação do vídeo amador feito com celular como repertório de resistência: da janela de casa, moradores filmaram policiais da UPP (Unidade de Polícia Pacificadora) alterando a cena de um crime ao colocar uma arma nas mãos de Eduardo Felipe e efetuar disparos com intenção de simular um confronto. Eduardo morreu no local e o caso foi registrado como "auto de resistência". O caso ganhou repercussão apenas pelo fato de haver o vídeo com o flagrante, uma vez que autos de resistência (agora chamado de "homicídio decorrente de oposição à ação policial") são rotineiros na ação da polícia nas favelas (MISSE, 2015).

\section{Conclusão}

A representação das favelas na mídia mainstream com viés negativo e estigmatizado permanece hegemônica (AMARAL, 2019). Com a popularização dos smartphones e redes sociais, que se consolidaram como principal ferramenta do "midiativismo de favela" (CUSTÓDIO, 2016), moradores com desejo compartilhado de melhores condições de vida nessas comunidades se uniram na luta contra a violência 


\section{miDiA

estrutural, manifestada principalmente através da violência policial, utilizando as redes sociais para tomar para si as narrativas da favela e desafiar a representação racializada e tendenciosa da grande mídia. Seja como ativistas, seja colaborando com ativistas e coletivos, os moradores das favelas cariocas encontram-se hoje envolvidos na utilização dessas redes em atos de protesto e em atividades de proteção coletiva (como a filmagem de cenas do crime e de ação policial e o sistema de avisos de conflitos em andamento observado no grupo Maré Vive), assim como na organização do dia-a-dia das favelas, incluindo eventos culturais e de solidariedade. O aprendizado, que agora já se consolida nas camadas mais jovens, vem gerando a cristalização de tais práticas, incorporadas como repertório de resistência nessas comunidades. As favelas, portanto, se emancipam pouco a pouco da representação midiática vigente através da atuação militante nas redes sociais, que se apresentam como uma das ferramentas de resistência na luta contra a criminalização e por espaço e valorização da cultura das favelas.

\section{Referências}

ABREU, Sabrina. A Voz Do Alemão: como Rene Silva e outros jovens ajudaram a mudar a imagem da comunidade / Sabrina Abreu e Rene Silva. São Paulo: nVersos, 2013.

AMARAL, Fernanda. They have something to say: a study of social media use and public discourse in the Rio de Janeiro favelas. Leicester: De Montfort University, 2019. Tese (Doutorado em Discurso de Mídia), Leicester Media School, De Montfort University, Leicester, 2019a.

AMARAL, Fernanda. Violence and impunity in Rio de Janeiro's favelas: citizens, smartphones and police malpractice. In: PRICE, Stuart (Ed.). Journalism, Power and Investigation Global and Activist Perspectives. London and New York: Routledge, 2019b. p. 160-174.

BARONI, Alice; AGUIAR, Leonel; RODRIGUES, Felipe. Novas configurações discursivas no jornalismo: narrativas digitais nas favelas do Rio de Janeiro. Estudos em Comunicação, n. 9, p. 309-327, 2011.

BOURDIEU, Pierre. The logic of practice. Stanford university press, 1990.

CAPRIGLIONE, Laura. Os mecanismos midiáticos que livram a cara dos crimes das polícias militares no Brasil. In: KUCINSKI, Bernando (Ed.). Bala perdida: a violência policial no Brasil e os desafios para sua superação. São Paulo: Boitempo, 2015. p. 55-60.

CASTELLS, Manuel. Networks of outrage and hope. 2ed. Cambridge: Polity, 2015. 
CHALHOUB, Sidney. Medo branco de alma negra: escravos, libertos e Republicanos na Cidade do Rio de Janeiro. Revista Brasileira De História, v.8, n. 16, pp. 83-105, 1988.

CUSTÓDIO, Leonardo da Costa. Midiativismo de Favela: Reflexões sobre o processo de pesquisa. Tampere: University of Tampere, 2016.

CUSTÓDIO, Leonardo da Costa. Offline dimensions of favela youth online reactions to human rights violations before Rio 2016. In: MOKSNES, Heidi. e MELIN, Mia. (Eds.). Claiming the city: civil society mobilisation by the urban poor. Uppsala: Uppsala University, 2014b, pp. 148154.

CUSTÓDIO, Leonardo da Costa. Tipos de midiativismo de favela. 2014a Disponível em: <http://eprints.lse.ac.uk/60663/>. Acesso em: 23 set. 2019.

DELLA PORTA, Donatella; DIANI, Mario. Social Movements: An Introduction. 2. ed. Malden and Oxford: Blackwell Publishing, 2006.

GIORGIS, Liliana. El "hombre" en las fronteras de la "identidad". Cordoba: Mimeo, 1993.

GOFFMAN, Erving. Frame Analysis: An essay on the organization of experience. New York: Harper \& Row, 1974.

HALL, Stuart. Representation: Cultural Representations and Signifying Practices. London: SAGE, 1997.

HARLOW, Summer. and GUO, Lei. Will the Revolution be Tweeted or Facebooked? Using Digital Communication Tools in Immigrant Activism. Journal of Computer-Mediated Communication, v. 19, n. 3, pp. 463-478, 2014.

HINE, Christine. Virtual Etnography. London: SAGE, 2000.

JENKINS, Henry. Cultura da Convergência. Tradução por Susana Alexandria. São Paulo: Aleph, 2008.

LAWY, Jenny R. Theorizing voice: Performativity, politics and listening. Anthropological Theory, v. 17, n. 2, p. 192-215, 2017.

LÉVY, Pierre. Cibercultura. São Paulo: Editora 34, 1999.

LOPES, Flávia Valério; ALVES, Wedencley. Discurso e redes sociais: o caso "Voz da comunidade". Ciberlegenda, n. 25, p. 111-123, 2011.

MACLEOD, Kirsten. Naw, naw, aye: Activism and Alternative media in the 2014 Scottish Referendum. In: PRICE, Stuart; SANZ SABIDO, Ruth. (Eds.) Sites of Protest. London and New York: Rowman \& Littlefield International, 2016. p. 89-105.

MACNAMARA, Jim. Media content analysis: Its uses; benefits and best practice methodology. Asia Pacific Public Relations Journal, v. 6, n. 1, p. 1-34, 2005. 
MAIBA, Hermann. (2005) Grassroots Transnational Social Movement Activism: The Case of Peoples' Global Action. Sociological Focus, v. 38, n. 1, p. 41-63, 2005.

MCCURDY, Patrick; FEIGENBAUM, Anna; FRENZEL, Fabian. Protest Camps and Repertoires of Contention. Social Movement Studies, v.15, n.1, p. 97-104, 2016.

MCLEOD, Douglas M; HERTOG, James K. Social control, social change and the mass media's role in the regulation of protest groups. In: DEMERS, David; KASISOMAYAJULA, Viswanath (Eds.) Mass Media, Social Control And Social Change: A Macrosocial Perspective. Ames: Iowa State University Press, 1999, p. 305-330.

MEIRELLES, Renato; ATHAYDE, Celso. Um país chamado favela. São Paulo: Editora Gente, 2014.

MENA, Fernanda. Um modelo violento e ineficaz de polícia. In: KUCINSKI, Bernando (Ed.). Bala perdida: a violência policial no Brasil e os desafios para sua superação. São Paulo: Boitempo, 2015. P. 19-26.

MISSE, Michel. Letalidade policial e indiferença legal: a apuração judiciária dos "autos de resistência" no Rio de Janeiro (2001-2011). DILEMAS: Revista de Estudos de Conflito e Controle Social - Edição Especial, n. 1, p. 43-71, 2015.

OPP, Karl-Dieter. Theories of political protest and social movements: A Multidisciplinary Introduction, Critique, and Synthesis. London: Routledge, 2009.

POLLETTA, Francesca; JASPER, James M. Collective Identity and Social Movements. Annual Review of Sociology, v. 27, n. 1, p. 283-305, 2001.

RAMOS, Silvia; PAIVA, Anabela. Mídia e violência: tendências na cobertura de criminalidade e segurança no Brasil. Rio de Janeiro: IUPERJ, 2007.

RINALDI, Alessandra de Andrade. Marginais, delinquentes e vítimas: um estudo sobre a representação da categoria favelado no tribunal do júri da cidade do Rio de Janeiro. In: ZALUAR, Alba; ALVITO, Marcos. Um século de favela. 5. ed. Rio de Janeiro: Editora FGV, 2006. p 299-322.

TACCHI, Jo. Finding a Voice: Digital Storytelling as Participatory Development. In: HARTLEY, John; MCWILLIAM, Kelly. Story Circle: Digital Storytelling Around the World. Massachusetts: Wiley-Blackwell, 2009. p 167-175.

TARROW, Sidney. Power in Movement: Social Movements and Contentious Politics. 2 ed. Cambridge: Cambridge University Press, 1998.

TERRA, José Maria; CARVALHO, Thiago Fabres de. Justiça Paralela. Rio de Janeiro: Editora Revan, 2015.

TILLY, Charles. From mobilization to revolution. New York: McGraw-Hill, 1978. 
VALENTE, Júlia Leite. "Polícia Militar" é um oximoro: A militarização da Segurança Pública no Brasil. Revista do Laboratório de Estudos da Violência e Segurança, n. 10, p. 204-224, 2012.

VALLADARES, Licia do Prado. A invenção da Favela. Rio de Janeiro: FGV Editora, 2005.

VAZ, Paulo; BAIENSE, Carla. Mídia e enquadramento: as representações da favela na virada do século XXI. In: VIII Encontro Nacional de História da Mídia, 08, 2011, Guarapuava. Anais [...] Paraná: Unicentro, 2011. Disponível em: 〈https://bit.ly/2OUdFYR>. Acesso em: 18 set. 2019.

VENTURA, Zuenir. Cidade Partida. São Paulo: Companhia das Letras, 1994.

WYLLYS, Jean. Formas de temer, formas de reprimir: as relações entre a violência policial e suas representações nas mídias. In: KUCINSKI, Bernando (Ed.). Bala perdida: a violência policial no Brasil e os desafios para sua superação. São Paulo: Boitempo, 2015. p. 51-54.

ZAFFARONI, Eugenio Raúl. La palabra de los muertos: conferencias de criminologia cautelar. Buenos Aires: Ediar, 2011.

ZALD, Mayer N; MCCARTHY, John D; GAMSON, William A. Social Movements in an Organizational Society. New Brunswick and London: Transaction publishers, 2017.

ZALUAR, Alba; ALVITO, Marcos. Um século de favela. 5. ed. Rio de Janeiro: Fundação Getúlio Vargas Editora, 2006.

ZHAO, Shanyang; GRASMUCK, Sherri; MARTIN, Jason. Identity construction on Facebook: Digital empowerment in anchored relationships. Computers in Human Behavior, n. 24, p. 1816-1836, 2008. 